\title{
Incidence of Anxiety and Depression Among Patients with Type 2 Diabetes and the Predicting Factors
}

\author{
Paeenda Khan ${ }^{1}$, Neyha Qayyum ${ }^{2}$, Farina Malik ${ }^{2}$, Tooba Khan ${ }^{1}$, Maaz Khan ${ }^{2}$, Amber Tahir ${ }^{3}$ \\ 1. Miscellaneous, Jinnah Sindh Medical University, Karachi, PAK 2. Internal Medicine, Jinnah Postgraduate Medical \\ Centre, Karachi, PAK 3. Internal Medicine, Dow University of Health Sciences, Karachi, PAK
}

Corresponding author: Amber Tahir, siddiquiambertahir@gmail.com

\section{Abstract \\ Introduction}

Diabetes mellitus (DM) is a chronic, progressive metabolic illness which is commonly complicated by coexistence of depression and anxiety. This study aimed to assess the prevalence of anxiety and depression among diabetic patients and the factors predicting this coexistence.

\section{Methods}

It was a cross-sectional, observational study which included patients of type $2 \mathrm{DM}$ admitted in the hospital due to diabetes-related condition - diabetic foot infections/ulcers, hyperosmotic hyperglycaemic state (HHS), and hypoglycaemic coma/seizure. Anxiety and depression were measured by using the Hospital Anxiety and Depression Scale (HADS). Data was entered and analysed using SPSS version 22.0 (IBM Corp., Armonk, NY, USA).

\section{Results}

Mean anxiety score of the participants was $10.88 \pm 4.075$ and mean depression score was $11.82 \pm 4.049$. There were 72 (50.7\%) patients who had anxiety and 70 (49.2\%) patients who had depression. Higher scores of anxiety and depression were statistically significant in female gender, older participants, individuals with longer duration of diabetes, those taking non-insulin treatment, and individuals with painful neuropathy, nephropathy, and foot ulcers.

\section{Conclusion}

The incidence of depression and anxiety among hospitalized patients of diabetes mellitus is high. The coexistence of these two chronic debilitating illnesses is worsening the overall quality of life. It is very important to diagnose and manage anxiety and depression in patients with type $2 \mathrm{DM}$ to ensure higher quality of life and life expectancy.

Received 03/08/2019

Review began 03/11/2019

Review ended 03/11/2019

Published 03/14/2019

() Copyright 2019

Khan et al. This is an open access article distributed under the terms of the Creative Commons Attribution License CC-BY 3.0., which permits unrestricted use, distribution, and reproduction in any medium, provided the original author and source are credited.
Categories: Endocrinology/Diabetes/Metabolism, Internal Medicine, Psychology

Keywords: hospital anxiety and depression scale, diabetes mellitus, type 2 diabetes mellitus, depression in diabetes, depression, anxiety, pakistan

\section{Introduction}

Diabetes mellitus (DM) is among the most common chronic metabolic illnesses and is characterized by elevated plasma glucose levels. Individuals living with DM become more prone to health complications, have an overall reduced quality of life, and result in higher burden on the economy due to their medical care expenditure [1]. In 2017, it was estimated that globally USD 850 billion has been spent on the healthcare of persons living with diabetes [2]. In 2018, there were 500+ million individuals living with type II DM globally. Although currently the prevalence is comparable in high-income and low-income countries; the expected rise in prevalence will be more aggressive in low-income countries [3].

According to World Health Organization (WHO), the global leading cause of disability is depression with 300 million individuals succumbing to this debilitating mental disorder [4]. Epidemiological studies have shown that coexistence of diabetes mellitus and depression is twice as frequent as either of these alone [5].

Diabetes-related risk factors that predispose to development of depression have been studied by many researchers. In people with type $2 \mathrm{DM}$, greater incidence of depression was seen in insulin-dependent individuals than those who were non-insulin dependent [6]. This implies that insulin-dependent individuals had more progressed disease and increased demand of treatment. As the disease further progresses and complications of diabetes ensue, especially painful peripheral neuropathy and sexual dysfunction, the 
incidence of depression in the individuals further rises [7]. Among all diabetic complications, neuropathy and nephropathy have been seen to be the strongest predictors of depression $[8,9]$.

Coexistence of depression and DM becomes a grave challenge for the clinicians as both illnesses worsen the outcome of each other. Combination of depression and DM reduces overall quality of life, impairs selfmanagement of diabetes, increases the risk of diabetic complications, and reduces overall life expectancy [10]. Diabetic patients with coexisting depression have reported higher $\mathrm{HbA1c}$, and more derangement in blood sugar levels [9]. In order to ensure an adequate quality of life, the multidimensional approach to manage diabetes mellitus should also take into consideration the mental health of these individuals and identifying the ones who are at risk of succumbing to the grave illness of depression. The aim of this study is to assess the frequency of depression in diabetic patients admitted in the hospital due to any diabetesrelated reason.

\section{Materials And Methods}

This observational, cross-sectional study was conducted in the department of general medicine, Jinnah Post Graduate Medical Centre, from October till December 2018. Known cases of type 2 diabetes mellitus, of both genders, who were admitted in the hospital (for minimum one day) for diabetes-related reasons including diabetic foot infections/ulcers, hyperosmotic hyperglycaemic state (HHS), and hypoglycaemic coma/seizure, were invited to participate in the study. Patients of type 1 diabetes, and those type 2 diabetics who had coexisting hypertension or cardiovascular disease were excluded to reduce bias. Hospital Anxiety and Depression Scale (HADS) [11] was utilized to assess the frequency of anxiety and depression in these patients. HADS is a 14-item self-administered instrument that has two subscales to assess anxiety and depression. Each subscale has seven items. Each item is evaluated on a four-point Likert scale. All scores are then added. A combine score of 0-7 indicates "no anxiety/depression," score of 8-10 indicates "moderate anxiety/depression,” and a score of 11-21 indicates "severe anxiety/depression.”

Along with HADS, a demographic performa was created which included patient gender, age, duration of DM, treatment of DM, complications of DM, duration of hospital admission, and the reason of admission. Data was entered and analysed using SPSS version 22.0 (IBM Corp., Armonk, NY, USA). Mean and standard deviation (SD) was calculated for continuous variables including patient age, duration of hospital stay, and mean scores of depression and anxiety on HADS. Internal consistency of both subscales of HADS was calculated using Cronbach's alpha. Frequencies and percentages were calculated for categorical variables such as gender, severity of depression and anxiety. Chi square was applied to compare severity of HADS with patient characteristics. p-value of $\leqslant 0.05$ was considered significant.

\section{Results}

The study was completed by 142 diabetic patients. The mean age of the participants was $57.01 \pm 11.23$ years (range: 45-71 years). Their mean duration of hospital stay was 3.14 \pm 1.58 days (range: $1-7$ days). Of all the participants, 61 (43\%) were males and 81 (57\%) were females. The demographic and clinical characteristics of the patients are shown in Table 1. 


\section{Cureus}

Patient characteristics

Frequency n (\%)

Gender

Male

$61(43 \%)$

Female

81 (57\%)

Age

Less than 50 years

$39(27.4 \%)$

More than 50 years

$103(72.5 \%)$

Duration of diabetes

Less than 10 years

$40(28.2 \%)$

More than 10 years

$102(71.8 \%)$

Treatment of diabetes

Insulin therapy

$48(33.8 \%)$

Non-insulin medications

$94(66.2 \%)$

Complications of diabetes

Peripheral painful neuropathy

$32(22.5 \%)$

Nephropathy

$17(11.9 \%)$

Retinopathy

$11(7.7 \%)$

Foot ulcers

$48(33.8 \%)$

Sexual dysfunction

No complication

$25(17.6 \%)$

Reason for admission

Infected diabetic foot ulcer

$43(30.2 \%)$

Hyperosmotic hyperglycaemic state

$52(36.6 \%)$

Hypoglycaemic coma/seizures

$47(33.1 \%)$

TABLE 1: Demographic and clinical characteristics of the patients $(n=142)$.

The internal consistency of HADS in this study was 0.78 . The internal consistency of subscale anxiety was 0.71 and that of subscale depression was 0.75 . Overall mean anxiety score was $10.88 \pm 4.075$ and mean depression score was $11.82 \pm 4.049$. There were 72 (50.7\%) patients who had anxiety and $70(49.2 \%)$ patients who had depression. The severity of their anxiety and depression on HADS is shown in Table 2. 


\section{Cureus}

Subscale of HADS

Frequency n (\%)

Anxiety

HADS score $>10$

Mild

Moderate

Severe

Depression

HADS score $>10$

Mild

Moderate

Severe
70 (49.2\%)

$16(22.8 \%)$

$29(41.4 \%)$

$72(50.7 \%)$

35 (48.6\%)

$19(26.3 \%)$

18 (25\%)

$25(35.7 \%)$

TABLE 2: Frequency and severity of anxiety and depression on HADS in patients with type 2 diabetes mellitus $(n=142)$.

HADS: Hospital Anxiety and Depression Scale

HADS scores of both subscales - anxiety and depression - were correlated with the demographic and clinical characteristics of the patients as shown in Table 3. It was seen that anxiety score of more than 10 was more common in female gender, older participants, individuals with longer duration of diabetes, those taking non-insulin treatment, individuals with painful neuropathy and nephropathy, and those admitted with HHS (Table 3).

On the other hand, higher score of depression on HADS was more common in women, older age participants, individuals with longer duration of diabetes, those taking non-insulin treatment, individuals with painful neuropathy and foot ulcers, and individuals admitted with those admitted with foot ulcers (Table 3). Except for age, the scores of HADS were statistically significant to all other demographic and clinical characteristics as shown in Table 3. 


\section{Cureus}

\begin{tabular}{|c|c|c|c|c|c|c|}
\hline \multirow{2}{*}{$\begin{array}{l}\text { Demographic and clinical } \\
\text { characteristics }\end{array}$} & \multicolumn{3}{|l|}{ Anxiety } & \multicolumn{3}{|l|}{ Depression } \\
\hline & $\begin{array}{l}\text { HADS score > } 10(n \\
=72)\end{array}$ & $\begin{array}{l}\text { HADS score }<10(n \\
=70)\end{array}$ & $\mathrm{p}$-value & $\begin{array}{l}\text { HADS score }>10(n \\
=70)\end{array}$ & $\begin{array}{l}\text { HADS score }<10(n \\
=72)\end{array}$ & $\begin{array}{l}\mathrm{p}- \\
\text { value }\end{array}$ \\
\hline \multicolumn{7}{|l|}{ Gender } \\
\hline Male & $22(30.5 \%)$ & 39 (55.7\%) & \multirow{2}{*}{0.002} & $24(34.2 \%)$ & 37 (51.4\%) & \multirow{2}{*}{0.03} \\
\hline Female & $50(69.5 \%)$ & $31(44.3 \%)$ & & $46(65.7 \%)$ & 35 (48.6\%) & \\
\hline \multicolumn{7}{|l|}{ Age } \\
\hline Less than 50 years & $18(25 \%)$ & $21(30 \%)$ & \multirow{2}{*}{0.50} & $22(31.4 \%)$ & $17(23.6 \%)$ & \multirow{2}{*}{0.29} \\
\hline More than 50 years & 54 (75\%) & 49 (70\%) & & 48 (68.5\%) & 55 (76.3\%) & \\
\hline \multicolumn{7}{|l|}{ Duration of diabetes } \\
\hline Less than 10 years & $9(12.5 \%)$ & 31 (44.2\%) & \multirow[b]{2}{*}{$<0.0000$} & $11(15.7 \%)$ & $29(40.2 \%)$ & \multirow[b]{2}{*}{0.001} \\
\hline More than 10 years & $63(87.5 \%)$ & $39(55.7 \%)$ & & $59(84.3 \%)$ & $43(59.8 \%)$ & \\
\hline \multicolumn{7}{|l|}{ Treatment of diabetes } \\
\hline Insulin therapy & $29(40.2 \%)$ & 19 (27.1\%) & \multirow{2}{*}{0.09} & $32(45.7 \%)$ & $16(22.2 \%)$ & \multirow{3}{*}{0.003} \\
\hline Non-insulin medications & $43(59.8 \%)$ & $51(72.8 \%)$ & & 38 (54.3\%) & 56 (77.7\%) & \\
\hline \multicolumn{6}{|l|}{ Complications of diabetes } & \\
\hline Peripheral painful neuropathy & $27(37.5 \%)$ & $5(7.1 \%)$ & \multirow{5}{*}{0.00071} & $22(31.4 \%)$ & $10(13.9 \%)$ & \multirow{5}{*}{0.008} \\
\hline Nephropathy & $9(12.5 \%)$ & $8(11.4 \%)$ & & $6(8.5 \%)$ & $11(15.3 \%)$ & \\
\hline Retinopathy & $3(4.2 \%)$ & $8(11.4 \%)$ & & $1(1.4 \%)$ & $10(13.9 \%)$ & \\
\hline Foot ulcers & $19(26.7 \%)$ & $29(41.4 \%)$ & & $25(35.7 \%)$ & $23(31.9 \%)$ & \\
\hline Sexual dysfunction & $5(6.9 \%)$ & $4(5.7 \%)$ & & $5(7.1 \%)$ & $4(5.5 \%)$ & \\
\hline \multicolumn{7}{|l|}{ Reason for admission } \\
\hline Infected diabetic foot ulcer & $26(36.1 \%)$ & $17(24.2 \%)$ & \multirow{3}{*}{0.000} & $29(41.4 \%)$ & $14(19.4 \%)$ & \multirow{3}{*}{0.01} \\
\hline $\begin{array}{l}\text { Hyperosmotic hyperglycaemic } \\
\text { state }\end{array}$ & $34(47.2 \%)$ & $18(25.7 \%)$ & & $19(27.1 \%)$ & $33(45.8 \%)$ & \\
\hline Hypoglycaemic coma/seizures & $12(16.6 \%)$ & $35(50 \%)$ & & $22(31.4 \%)$ & $25(34.7 \%)$ & \\
\hline
\end{tabular}

TABLE 3: HADS score of anxiety and depression categorized according to the demographic and clinical characteristics of the patients $(n=142)$.

HADS: Hospital Anxiety and Depression Scale

\section{Discussion}

Diabetes mellitus is a chronic, progressive, metabolic illness and superimposed depression further debilitates the overall health-related quality of life and life expectancy of these individuals. Almost half of the study participants in this survey were anxious and depressed. The associated factors included female gender, longer duration of diabetes, non-insulin treatment, complications including neuropathy, nephropathy, and foot ulcers, and admission due to infected foot ulcers, HHS, and hypoglycaemic coma.

The outcomes of this study are comparable to those existing in the literature and reinforce the higher incidence of anxiety and depression in type 2 DM patients. In a study conducted in Tunisia, $40 \%$ of elderly diabetics were anxious and $22 \%$ were depressed [12]. Khuwaja et al. in their study reported the incidence of depression and anxiety to be $44 \%$ and $58 \%$, respectively [13]. However, in the western countries the reported incidence of depression and anxiety among diabetics is slightly lower. Collins et al. utilized HADS in their study and reported $32 \%$ diabetics to be depressed and $22 \%$ anxious [14]. 
The diabetes-related factors predicting the incidence of depression reported in this study correspond to other existing literature. Painful peripheral diabetic neuropathy has been repeatedly reported to be associated with onset of depression $[9,15]$. This association can be well explained by the underlying neurochemical imbalance [16]. Although other studies have reported incidence of depression to be higher in diabetics who are dependent on insulin for their treatment [12, 17], our study reported different outcomes. This may imply that this association might not be valid for Pakistani population or maybe the individuals being managed with oral hypoglycaemic agents need to be switched to insulin therapy for better control and more promising outcomes. Since we could not find any Pakistani study reporting this association, we would recommend larger, multiple studies to strengthen this association. This study is in no way enough to establish that depression is more common in non-insulin dependent individuals.

While this study adds to the limited data available regarding anxiety and depression among hospitalized patients with type $2 \mathrm{DM}$, it has its limitations too. Since it is a cross-sectional study, a causal relationship between diabetes and symptoms of anxiety and depression cannot be proven or established. Another limitation is that, instead of a structured interview to evaluate anxiety and depression, a psychometric scale was utilized which makes it hard to include physical aspect of psychiatric symptoms. The survey was only conducted among hospitalized patients who might have higher prevalence of anxiety and depression than non-hospitalized diabetic patients.

Despite these limitations, as suggested by this study and supported by the global data, the coexistence of these two chronic debilitating illnesses is worsening the overall quality of life. It is very important to diagnose and manage anxiety and depression in patients with type $2 \mathrm{DM}$, which is only possible with a collaborative effort of diabetologists, general physicians, and psychiatrists.

\section{Conclusions}

The incidence of depression and anxiety among hospitalized patients of diabetes mellitus is high. Strong predictors of depression in patients with diabetes include female gender, longer duration of diabetes, noninsulin treatment, and complications including neuropathy, nephropathy, and foot ulcers. The coexistence of these two chronic debilitating illnesses is worsening the overall quality of life. It is very important to diagnose and manage anxiety and depression in patients with type $2 \mathrm{DM}$, which is only possible with a collaborative effort of diabetologists, general physicians, and psychiatrists.

\section{Additional Information \\ Disclosures}

Human subjects: Consent was obtained by all participants in this study. Animal subjects: All authors have confirmed that this study did not involve animal subjects or tissue. Conflicts of interest: In compliance with the ICMJE uniform disclosure form, all authors declare the following: Payment/services info: All authors have declared that no financial support was received from any organization for the submitted work. Financial relationships: All authors have declared that they have no financial relationships at present or within the previous three years with any organizations that might have an interest in the submitted work. Other relationships: All authors have declared that there are no other relationships or activities that could appear to have influenced the submitted work.

\section{References}

1. Baena-Diez JM, Penafiel J, Subirana I, et al.: Risk of cause-specific death in individuals with diabetes: a competing risks analysis. Diabetes Care. 2016, 39:1987-1995. 10.2337/dc16-0614

2. Cho NH, Shaw JE, Karuranga S, Huang Y, da Rocha Fernandes JD, Ohlrogge AW, Malanda B: IDF Diabetes Atlas: global estimates of diabetes prevalence for 2017 and projections for 2045. Diabetes Res Clin Pract. 2018, 138:271-281. 10.1016/j.diabres.2018.02.023

3. Kaiser AB, Zhang N, van der Pluijm WO: Global prevalence of type 2 diabetes over the next ten years (20182028). Diabetes. 2018, 67:10.2337/db18-202-LB

4. Depression. (2018). Accessed: March 7, 2019: https://www.who.int/news-room/factsheets/detail/depression.

5. Anderson RJ, Freedland KE, Clouse RE, Lustman PJ: The prevalence of comorbid depression in adults with diabetes: a meta-analysis. Diabetes Care. 2001, 24:1069-1078. 10.2337/diacare.24.6.1069

6. Li C, Ford ES, Strine TW, Mokdad AH: Prevalence of depression among U.S. adults with diabetes: findings from the 2006 behavioral risk factor surveillance system. Diabetes Care. 2008, 31:105-107. 10.2337/dc071154

7. de Groot M, Anderson R, Freedland KE, Clouse RE, Lustman PJ: Association of depression and diabetes complications: a meta-analysis. Psychosom Med. 2001, 63:619-630.

8. van Steenbergen-Weijenburg KM, van Puffelen AL, Horn EK, et al.: More co-morbid depression in patients with Type 2 diabetes with multiple complications. An observational study at a specialized outpatient clinic. Diabet Med. 2011, 28:86-89. 10.1111/j.1464-5491.2010.03125.x

9. Bajaj S, Agarwal SK, Varma A, Singh VK: Association of depression and its relation with complications in newly diagnosed type 2 diabetes. Indian J Endocr Metab. 2012, 16:759-763. 10.4103/2230-8210.100670

10. Holt RI, Katon WJ: Dialogue on diabetes and depression: dealing with the double burden of co-morbidity . J Affect Disord. 2012, 142:S1-S3. 10.1016/S0165-0327(12)00632-5 


\section{Cureus}

11. Stern AF: The hospital anxiety and depression scale. Occupational Med. 2014, 64:393-394. 10.1093/occmed/kqu024

12. Masmoudi J, Damak R, Zouari H, Ouali U, Mechri A, Zouari N, Jaoua A: Prevalence and impact of anxiety and depression on type 2 diabetes in Tunisian patients over sixty years old. Depress Res Treat. 2013, 2013:6. $10.1155 / 2013 / 341782$

13. Khuwaja AK, Lalani S, Dhanani R, Azam IS, Rafique G, White F: Anxiety and depression among outpatients with type 2 diabetes: a multi-centre study of prevalence and associated factors. Diabetol Metab Syndr. 2010, 2:72. 10.1186/1758-5996-2-72

14. Collins MM, Corcorant P, Perry IJ: Anxiety and depression symptoms in patients with diabetes . Diabet Med. 2009, 26:153-161. 10.1111/j.1464-5491.2008.02648.x

15. D'Amato C, Morganti R, Greco C, et al.: Diabetic peripheral neuropathic pain is a stronger predictor of depression than other diabetic complications and comorbidities. Diab Vasc Dis Res. 2016, 13:418-428. $10.1177 / 1479164116653240$

16. Dziemidok P, Dąbrowski M, Makara-Studzińska M: Relationship between diabetic neuropathy and occurrence of depression among diabetic patients. Psychiatr Pol. 2016, 50:407-415.

10.12740/PP/OnlineFirst/42352

17. Bai X, Liu Z, Li Z, Yan D: The association between insulin therapy and depression in patients with type 2 diabetes mellitus: a meta-analysis. BMJ Open. 2018, 8:020062. 10.1136/bmjopen-2017-020062 